\title{
POSITRON TRAPPING RATE COEFFICIENT FOR THERMALIZED POSITRONS AT METAL-DIELECTRIC INTERFACE *
}

\author{
A. Baranowski, R. EWERTowski, W. ŚWiątKowski \\ Institute of Experimental Physics, Wrocław University, ul. Cybulskiego 36, \\ 50-205 Wrocław, Poland \\ (Received November 28, 1989; in revised version September 14, 1990) \\ On the basis of experimental positron lifetime spectra it was shown that \\ positrons can be trapped at metal-dielectric interface. The coefficient indi- \\ cating the trapping possibility of the $\mathrm{AgNa}_{3} \mathrm{AlF}_{6}$ interface has been evalu- \\ ated.
}

PACS numbers: $68.35 . \mathrm{Wn}$

\section{Introduction}

According to the image potential model of the interaction of positrons with a metal surface thermalized positrons which are able to reach the surface can be surfacely trapped [1-3]. It seemed likely that similar trapping could take place in the case of a metal-dielectric interface. One consequence of such trapping was the expectation of an anisotropy of the distribution of momenta of photon pairs appearing when the surfacely trapped positrons annihilated. Using multilayer metal-dielectric samples and orienting them in two ways with respect to the pair-momentum annihilation spectrometer axis we had observed such anisotropy $[4,5]$. Another expectation was a possibility that the trapping of the positrons at the interface could give a special component in the positron lifetime spectrum. The measurements of the positron lifetime spectra, the one for an evaporated $\mathrm{Ag}$ sample and the second one for a multilayer $\mathrm{Ag} / \mathrm{Na}_{3} \mathrm{AlF}_{6}$ sample consisting of many alternating $\mathrm{Ag}(\sim 200 \mathrm{~nm})$ and $\mathrm{Na}_{3} \mathrm{AlF}_{6}(\sim 4 \mathrm{~nm})$ layers, obtained by evaporation, gave two different spectra (Table) [6].

${ }^{*}$ Work supported by the Ministry of National Education within the research project CPBP 01.08A. 
TABLE

Characteristics of positron lifetime spectra for $\mathrm{Ag}$, $\mathrm{Ag} / \mathrm{Na}_{3} \mathrm{AlF}_{6}$ and $\mathrm{Na}_{3} \mathrm{AlF}_{6}\left({ }^{a)}\right.$ data taken from [6]).

\begin{tabular}{c|c|c|c}
\hline \hline Sample & $\left.\mathrm{Ag}^{a}\right)$ & $\left.\mathrm{Ag}^{a} \mathrm{Na}_{3} \mathrm{AlF}_{6}{ }^{a}\right)$ & $\mathrm{Na}_{3} \mathrm{AlF}_{6}$ \\
\hline $2 \mathrm{I}_{1}$ & $(76.8 \pm 0.7) \%$ & $(56.6 \pm 8.5) \%$ & $(85.1 \pm 0.3) \%$ \\
$\tau_{1}$ & $(201 \pm 10) \mathrm{ps}$ & $(210 \pm 15) \mathrm{ps}$ & $(296 \pm 6) \mathrm{ps}$ \\
$\mathrm{I}_{2}$ & $(23.2 \pm 0.7) \%$ & $(42.5 \pm 8.5) \%$ & $(14.9 \pm 0.3) \%$ \\
$\tau_{2}$ & $(325 \pm 20) \mathrm{ps}$ & $(372 \pm 21) \mathrm{ps}$ & $(576 \pm 24) \mathrm{ps}$
\end{tabular}

The small amount of $\mathrm{Na}_{3} \mathrm{AlF}_{6}\left(\sim 0.5\right.$ weight $\%$ ) in the $\mathrm{Ag} / \mathrm{Na}_{3} \mathrm{AlF}_{6}$ sample, in form of thin layers separating the $\mathrm{Ag}$ layers, caused relatively large changes in the spectrum for this sample as compared with that one observed for the Ag sample. This result agrees with the assumption of a possibility of the positron trapping at the interface. In this paper we report additional experiments and analysis connected with this problem.

\section{Positron motion at metal-dielectric interface}

The basis of the interpretation of the results obtained in [4-6] was the assumption that there exists a potential "trough" for positrons at a metal-dielectric interface, and that positrons reaching the interiace during their diffusive movement in a metal can be trapped in the "trough". Of course one can not exclude other possibilities for the positron reaching the interface. By an analysis of the problem one should consider such possibilities:

1) Positron trapping in the "trough";

2) Reflection of positrons from the interface;

3) Penetration of positrons through the interface from metal to dielectric layers;

4) Penetration of positrons through the interface from dielectric to metal layers.

It is not likely that processes 3 and 4 can take place simultaneously. Even a small difference of thermalized positron potential energy in contacting metal and dielectric layers should allow positrons to penetrate the interface in a one direction only, as it was observed in the case of metal-metal interfaces $[7,8]$. Because of a very small amount of the dielectric $\left(\mathrm{Na}_{3} \mathrm{AlF}_{6}\right)$ in the $\mathrm{Ag} / \mathrm{Na}_{3} \mathrm{AlF}_{6}$ sample, only about one per cent fraction of positrons implanted in the sample was stopped in the dielectric layers. Thus a possibility of a penetration of positrons from the dielectric layers to the metal ones could not affect the positron lifetime spectrum perceptibly. Only the positron trapping at the interface and the penetration of positrons from the $\mathrm{Ag}$ layers to the $\mathrm{Na}_{3} \mathrm{AlF}_{6}$ ones could have caused the lifetime spectrum for the $\mathrm{Ag} / \mathrm{Na}_{3} \mathrm{AlF}_{6}$ sample to be different from that for the Ag sample.

In the case of the penetration of positrons to the dielectric layers one should expect the lifetime spectrum for the $\mathrm{Ag} / \mathrm{Na}_{3} \mathrm{AlF}_{6}$ sample to have components with lifetimes characteristic of the dielectric. To prove whether such situation takes place it was suitable to measure the lifetime spectrum for $\mathrm{Na}_{3} \mathrm{AlF}_{6}$. Using the same positron lifetime spectrometer as by obtaining of the lifetime spectra for the $\mathrm{Ag}$ and $\mathrm{Ag} / \mathrm{Na}_{3} \mathrm{AlF}_{\mathfrak{c}}$ samples we obtained the lifetime spectrum for the $\mathrm{Na}_{3} \mathrm{AlF}_{6}$ sample. Characteristics of this spectrum are collected in the Table. As 
it is easily seen from this Table it is impossible to explain, even partially, the difference between the spectrum for $\mathrm{Ag} / \mathrm{Na}_{3} \mathrm{AlF}_{6}$ and that one for $\mathrm{Ag}$ by assuming that essential fraction of positrons had annihilated in the dielectric layers. Thus it seemed reasonable to ascribe the observed changes as resulting from the positron trapping at the interface.

\section{The fraction of positrons annihilating as being surfacely trapped}

Let us assume that observed lifetime spectrum for the $\mathrm{Ag} / \mathrm{Na}_{3} \mathrm{AlF}_{6}$ sample can be treated as a superposition of the spectrum characteristic of evaporated Ag, say, with an intensity $I_{\mathrm{Ag}}$, and one-component spectrum connected with annihilation of surfacely trapped (at the interface) positrons, say, with an intensity $I_{3}$. Of course

$$
I_{\mathrm{Ag}}+I_{3}=1 \text {. }
$$

The lifetime spectrum for evaporated $\mathrm{Ag}$ has two components with respective lifetimes being larger than that one for bulk $\mathrm{Ag}$. This spectrum can be treated as conditioned by large rates of trapping to two kinds of traps (say, kind 1 and kind 2) existing in evaporated $\mathrm{Ag}$. The presence of additional traps in the $\mathrm{Ag} / \mathrm{Na}_{3} \mathrm{AlF}_{6}$ sample should not change the lifetimes characterizing positron annihilation in evaporated $\mathrm{Ag}$ and the ratio between respective component intensities. It means that

$$
\left(I_{1} / I_{2}\right)_{\mathrm{Ag}}=\left(I_{1}\right)_{\mathrm{Ag} / \mathrm{Na}_{3} \mathrm{AlF}_{6}} /\left(I_{2, \mathrm{Ag}}\right)_{\mathrm{Ag} / \mathrm{Na}_{3} \mathrm{AlF}_{6}},
$$

where $\left(I_{2, \mathrm{Ag}}\right)_{\mathrm{Ag}_{\mathrm{B}} / \mathrm{Na}_{3} \mathrm{AlF}_{6}}$ denotes the intensity of that fraction of the spectrum for $\mathrm{Ag} / \mathrm{Na}_{3} \mathrm{AlF}_{6}$ sample which is connected with annihilation of positrons as being trapped in traps of the kind 2 . It means that

$$
\left(I_{2}\right)_{\mathrm{Ag}_{\mathrm{g}} / \mathrm{Na}_{3} \mathrm{AlF}_{6}}=\left(I_{2, \mathrm{Ag}}\right)_{\mathrm{Ag}_{\mathrm{Aga}} \mathrm{NaFF}_{6}}+I_{3} .
$$

Because of limited resolution in measurements the two components were recorded as one component with summarized intensity and with an intermediate lifetime. This lifetime $\left[\left(\tau_{2}\right)_{\mathrm{Ag} / \mathrm{Na}_{3} \mathrm{AlF}}\right]$ should fulfil the equation

$$
\left(\tau_{2}\right)_{\mathrm{Ag} / \mathrm{Na}_{3} \mathrm{AlF}_{6}}=\left[\left(\tau_{2}\right)_{\mathrm{Ag}}\left(I_{2, \mathrm{Ag}}\right)_{\mathrm{Ag}_{\mathrm{g}} / \mathrm{Na}_{3} \mathrm{AIF}}+\tau_{3} I_{3}\right] \frac{1}{\left(I_{2}\right)_{\mathrm{Ag}_{\mathrm{g}} / \mathrm{Na}_{3} \mathrm{AlF}_{6}}},
$$

where $\tau_{3}$ denotes the lifetime of positrons trapped at the interface. Solution of the above equation system with respect to $\tau_{3}$ and $I_{3}$ gives $\tau_{3}=400 \mathrm{ps}$ and $I_{3}=0.254$. It means that about $P=0.254$ of positrons implanted in the $\mathrm{Ag} / \mathrm{Na}_{3} \mathrm{AlF}_{6}$ sample annihilated as surfacely trapped. It should be mentioned that the probability of trapping in a given kind of traps is somewhat less than the intensity of respective lifetime spectrum component (e.g. here $P<I_{3}$ ). However for a situation when almost all positrons annihilate as being trapped (saturation of trapping) the difference may be very small. In our further considerations we are taking $P$ is equal to 0.254 . 


\section{The diffusion model of positron trapping at the layer boundary}

The fraction of positrons implanted in a layer which can be surfacely trapped in the layer boundary depends both on the possibility of positrons to reach the boundary and on the boundary possibility to trap or to reflect the positrons. If one considers the layer which thickness (say $2 R$ ) is small as compared with positron absorption range, the implantation rate $S$ for such layer may be treated as independent of a distance from the layer boundary. Let's denote by $x$ coordinate being perpendicular to the layer surface with $x=0$ and $x=2 R$ for the two layer boundaries. The equilibrium positron concentration $\Phi$ in the layer should fulfil the one-dimentional diffusion equation

$$
\frac{d^{2} \Phi}{d x^{2}}-\frac{\Phi}{L^{2}}+\frac{S}{D}=0
$$

where $D$ is the positron diffusion constant and $L$ the effective positron diffusion length (conditioned as by free positron annihilation rate as by trapping rates to the defects). The boundary conditions related to Eq. (5) depend on the situation for positrons at layer limits, in our case on the possibilities of the interface to trap or to reflect the positrons reaching it. These possibilities (as the only two taking place) can be characterized by the coefficient $\beta$, which will be further called the positron trapping rate coefficient, and fulfil equations

$$
\beta \Phi(0)=+D\left[\frac{d \Phi}{d x}\right]_{x=0}
$$

and

$$
\beta \Phi(0)=-D\left[\frac{d \Phi}{d x}\right]_{x=2 R}
$$

where the right hand parts of the equations are the consequence of the Fick's law. As $\beta$ approaches zero the interface is totally reflecting (i.e. no trapping) and as $\beta$ approaches infinity, the interface is totally absorbing. Solving Eq. (5), with Eqs. (6) and (7) as its boundary conditions, one obtains

$$
\Phi=C_{-} e^{-x / L}+C_{+} e^{x / L}+\frac{S L^{2}}{D}
$$

where

$$
C_{\mp}=-\frac{S L^{2}}{D}-\frac{e^{ \pm R / L}}{e^{R / L}+e^{-R / L}+k\left(e^{R / L}-e^{-R / L}\right)}
$$

with

$$
k=\frac{D}{\beta L} .
$$

It is easy to see that for $k=\infty$, i.e. when the interface is totally reflecting $\Phi=$ const over all layer. The dependence of $\Phi$ on the distance from the layer central surface is presented in Fig. 1 for two $L / R$ ratios and for some $k$ values. As it is seen, the 

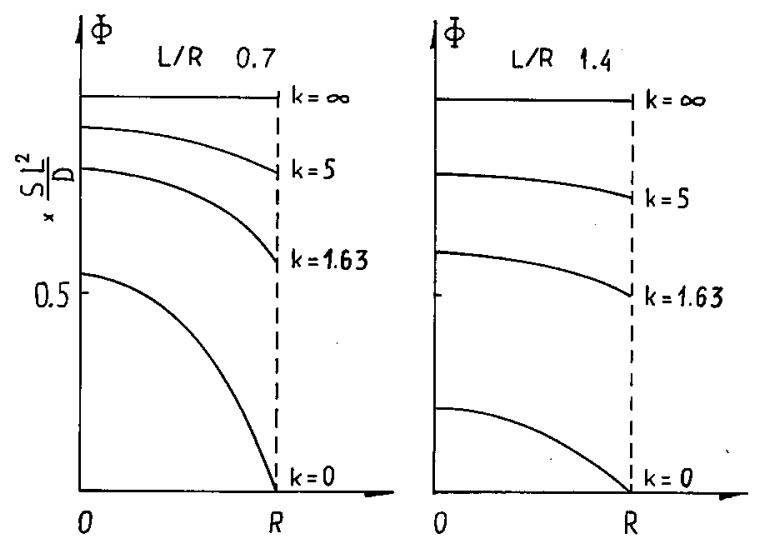

Fig. 1. The equilibrium positron concentration in the metal layer calculated for two $L / R$ values and for some different boundary conditions (different $k$ values).

larger $k$ the more uniformly are positrons distributed in the layer (for equilibrium situation).

Using Eq. (8) one can calculate the probability of the positron implanted in the metal layer to be trapped at its boundary. It is easy to show that this probability is given by the formula

$$
P(k)=\frac{\beta \Phi(0)+\beta \Phi(2 R)}{2 S R}=\frac{L}{R} \frac{e^{R / L}-e^{-R / L}}{e^{R / L}+e^{-R / L}+k\left(e^{R / L}-e^{-R / L}\right.} .
$$

For $k=0$ i.e. for $\beta=\infty$ (totally trapping interface) this formula has form [9]

$$
P(0)=\frac{L}{R} \tanh \left(\frac{R}{L}\right)
$$

The effective positron diffusion length for evaporated Ag layers was experimentally estimated earlier by Świątkowski et al. [7]. The Authors obtained some different values for $L$ in different series of experiment, the mean of them being close to $70 \mathrm{~nm}$. Even for the smallest of them the probability of trapping of positrons at the Ag layer boundaries, as calculated using formula (11) with $R=100 \mathrm{~nm}$ (characteristic of the $\mathrm{Ag}$ layer in the $\mathrm{Ag} / \mathrm{Na}_{3} \mathrm{AlF}_{6}$ sample), was much larger $(\sim 0.5)$ than the one evaluated in this paper from the experimental data (0.254). Thus one should treated the $\mathrm{Ag} / \mathrm{Na}_{3} \mathrm{AlF}_{6}$ interface as being partially absorbing and partially reflecting for positrons. By taking $L=70 \mathrm{~nm}, 2 R=200 \mathrm{~nm}$ and $P(k)=0.254$ one can show that the formula (10) can be valid with $k=1.63$. The positron diffusion coefficient for $\mathrm{Ag}$ is not known. The theoretically evaluated $\mathrm{D}$ values for different metals [10] (being in relatively good agreement with experiment) lay in $(0.3-0.7) 10^{-4} \mathrm{~m}^{2} \mathrm{~s}^{-1}$ region. Taking in formula (10) D is equal to $0.5 \times 10^{-4} \mathrm{~m}^{2} \mathrm{~s}^{-1}$ one obtains $\beta=440 \mathrm{~m} / \mathrm{s}$. 
There are no, up to now in literature, estimations of positron trapping rate coefficient $\beta$ (nor similar one) for thermalized positrons at metal-dielectric interface. However discussing experiments with positron trapping at the metal grain surfaces [11] Brandt [12] suggested the reflection of thermalized positrons reaching, as a result of their diffusion movement in metallic grain volume, the metal-vacuum surface. In 1980 Nieminen at al. [13] presented paper in which they had evaluated the possibility of positron to be trapped or reflected when it reached the bondary of the void formed in Al. They obtained, on the basis of positron lifetime measurements for Al containing voids, the temperature dependence of the coefficient $\gamma$ called by them the specific trapping rate.This coefficient after dividing by the void surface area is equivalent to the defined in this paper coefficient $\beta$. The $\beta$ values (for metal-vacuum surface) resulting from the data of [13] change from $0.95 \times 10^{3} \mathrm{~m} / \mathrm{s}$ for $T \approx 0 \mathrm{~K}$ to $3.0 \times 10^{3} \mathrm{~m} / \mathrm{s}$ for $T=300 \mathrm{~K}$.

\section{Final remarks}

The considerations presented above were done with the assumption that the $\mathrm{Ag} / \mathrm{Na}_{3} \mathrm{AlF}_{6}$ interface was well defined. Really the $\mathrm{Ag} / \mathrm{Na}_{3} \mathrm{AlF}_{6}$ sample used in the analysed experiments $[5,6]$ was obtained by evaporation in vacuum $10^{3} \mathrm{~Pa}$ which does not warrant such possibility. Nevertheless the observed positron annihilation characteristics seem to indicate the possibility of the positron trapping at the interface region. Especially, the observed anisotropy of the annihilation-photon-pair-momenta distribution [5] can be hardly explained without an assumption of the existing of strongly anisotropic traps for positrons. This caused us to do presented in this work analysis of the experimental results.

Of course the conditions of the sample preparation allows one to be not quite sure that the given interpretation is fully correct. The performance of a similar experiment with a monoenergetic positron beam and a single, well defined, metal-dielectric interface could give more certain results.

\section{References}

[1] C.H. Hodges, M.J. Stott, Solid State Commun. 12, 1135 (1973).

[2] W. Triftshäuser, D. Mc Gervey, R.W. Hendricks, Phys. Rev. B 9, 3321 (1974).

[3] B. Rozenfeld, K. Jerie, W. Świątkowski, Acta Phys. Pol. A54, 93 (1983).

[4] R. Ewertowski, W. Świątkowski, Phys. Scr. 35, 754 (1987).

[5] R. Ewertowski, W. Świątkowski, Phys. Status Solidi A 102, 555 (1987).

[6] R. Ewertowski, A. Baranowski, W. Świątkowski, Phys. Status Solidi $A$ 110, K101 (1988).

[7] W. Światkowski, B. Rozenfeld, H.B. Kołodziej, S. Szuszkiewicz, Acta Phys. Pol. A47, 79 (1975). 
[8] W. Świątkowski, Acta Univ. Wratislav. Mat. Fiz. Astron. 39, 1 (1982).

[9] W. Świątkowski, Nukleonika 24, 219 (1979).

[10] B. Bergersen, E. Pajanne, P. Kubica, M.J. Stott, C.H. Hodges, Solid State Commun. 15, 1377 (1974).

[11] R. Paulin, R. Ripon, W. Brandt, Appl. Phys. 4, 343 (1974).

[12] W. Brandt, Appl. Phys. 5, 1 (1974).

[13] R.M. Nieminen, J. Laakkonen, P. Hautojarvi, A. Vehanen, Phys. Rev. B 19, 1397 (1979). 